\title{
An Exploratory Analysis of English Teaching and Learning Model Using Mobile Equipment and Multimedia Tools in High Education in China
}

\author{
Zhou Lei ${ }^{1}$ \\ ${ }^{1}$ Shandong Yingcai University College of Foreign Languages and International Exchange
}

Key words: Mobile Learning; Multimedia Tools; Teaching and Learning Model; Elements and Procedures of Mobile Learning

\begin{abstract}
Considering the rapid development of computer techniques, information and communication technology is being increasingly used in curricula and the current situation that students in higher education system who are spending more time on their smart phones and internet, which accordingly spending less time on English learning by books in and after class, the writer investigates the actual facts to find out how to follow the trend and help guide students to learn English more effectively with the assistance of multimedia tools such as appliances on smart phones, software on computer via Internet, etc. The writer establishes a three-dimensional teaching and studying mode of methods to help improve students' ability of listening, speaking, reading, writing and translating. Meanwhile, the demanding condition of the fierce competition requires that university students would have focused on improving their real level of English especially the complex ability of English and their majors. This leads to the project that is ongoing--the advantages of modern teaching and learning model with the aid of multimedia devices and appliances comparing the traditional English learning model.
\end{abstract}

\section{The Background Information}

Until 2012, Chinese mobile phone users has reached to 1 billion, among which users who use Mobile phones to surf on Internet accounted for more than one third. This suggests that mobiles had become top one Internet terminal over desktop computers. Till the Second quarter of 2012, Chinese smart phone users had reached to 290 million.

Mobile learning can date back to late 90s in last century. Since its born, it expands so fast that now it has been in the stage of maturing. In recent years, with the rapid development of mobile computing, a brand new learning model appeared, namely m-learning. M-learning is a combination of new digital learning forms with the evolution of mobile technology and digital technology. European countries and America generally name it as m-Learning or m-Education, while in our country, it is described as Mobile Learning or Mobile Education. Mobile learning thoroughly break the limits of practice and space of studying, realizing the new experience of anyone learning at any time at any place which strongly support the cultivation of innovating talents and broad studying. The challenge we are going through in the future of language education is how to combine language learning theory and mobile techniques dynamically to discover the appropriate measures to make sure the situational method, individuation and cooperation of language study, realizing the continuity and even lifelong study pattern. In other words, it is vital to research how to realize the real learner-centered study pattern fully and technically. University students, as an essential component of groups to be more mature, more active and easier to accept new things, is well adequate for adopt new methods and tools to study, especially the commonly-used mobile equipment and technology. Moreover, college English is a compulsory subject in most universities and colleges. The Teaching Requirements of College English Course in 2007 referred that all the advanced colleges should fully take advantage of modern information technology and adopt English teaching pattern based on both computer and traditional class to improve the previous simplification of teaching pattern mainly based on teachers' lecturing. The new teaching pattern should be supported by modern information techniques especially network technology to infinitize the teaching and learning of English without the limits of time and location, moving forward to the development of individuation and self-study. Mobile learning of languages could be applied to the 
requirements of teaching and learning of college English courses rationally and effectively to a certain extent.

\section{The Theory Evidence and Current Research Situation Home and Abroad of Mobile Learning of Language}

There is no universal and specific definition right now for mobile learning. The experts and professional hold different ideas which could be classified into three types. The first catalog is to comprehend mobile learning as a type of distance learning, as distance learning educator Desmond Keegan referring that distance learning, digital learning and mobile learning are the three developing stages in distance education; the second one is to consider mobile learning is the extended form of digital learning, with their learning content and digital learning methods similar to each other and only being different in the way of obtaining information and knowledge via mobile communication network and mobile communication equipment; the third one is to focus on the content and forms, from the perspectives of cognization and study to research, mobile learning have no essential distinction with digital learning and network learning, but its characteristics of mobility and circumstances relevant make it totally different from digital learning and network learning and come to a brand new learning technique and pattern.

Mobile learning is the specific application of mobile broadband multimedia communication technology in education, so the practice of mobile learning should be guided by new-style learning theory. Mobile learning has relatively close relationship with the theories of informal learning, situational learning, environment learning, experimental learning. These new-style learning theories provide the practice of mobile learning with necessary and essential support; Meanwhile, mobile learning offers technique measures and tools of practical application for the above learning theories as well. Mobile learning of languages underlines the positive influence of learning environment on the learners and lay emphasis on the effective use of learning resources and materials in an era of information technology. This implies that learning theory transfers from the paradigm of conveying and behaviorism to constructirism and social cognitive paradigm and put the active learners in the centre of learning activities (Josie Taylor, 2002). Social cognitive theory of learning claims that learning exists in certain social context, and the construction and reconstruction of concepts occur not only at the level of individuals but also at the level of cooperated teams and partners who interact together to help the construction of concept building and schema of cognition (Rogers, 2002). These are the theories that mobile language learning based on.

\section{Research Status of Mobile Assisted Language Learning at Home and Abroad}

The research for mobile learning begins in America and now attracts much attention in many countries in the world. European countries and America have a wide range of scope and content of researches. The researchers hope to promote the way of mobile learning to developers of related mobile learning in the market and various educational institutions including higher education institutions who aim at help learners achieve their goals effectively. The project of Wireless Andrew (later renamed Handheld Andrew) in Carnegie Mellon University in USA was operated on the very first stage of all as the research on mobile learning. The first step of research of M-learning in Euro was raised by UK and sponsored by European Union with the joint efforts of UK, Italy and Swiss, mainly to solve the problem of inequity in education and to provide support to those who have difficulties to join in regular education or training.

With the complexity of language learning, the research for Mobile Assisted Language Learning, MALL is one step behind the whole progress of mobile learning. However, it has become an independent research field out of traditional language learning and Computer Assistant Language Learning, CALL. Some scholars would divide the research of MALL into two classes: one is focused on content, which develops learning activities and materials based on mobile equipment; the other is concentrated on the design of learning materials and activities suitable for mobile equipment. 
At present, one kind of the research groups is mainly formed by scholars, teachers and postgraduates major in education technology who are doing some basic appliances research and the other group is from business practice from business organizations, websites and publishing companies, which provides mobile assisted language learning courses to users.

Although certain achievements have been obtained at home and abroad, the systematic research is not deep enough and unorganized with less effective planning and we have a long way to go with the development of world researches. However, the widespread popularization of wireless communication technology and $3 G$ network lays a solid foundation for the practice of the development of mobile learning.

\section{The Research Objectives of Mobile English Learning}

The objective of this search is to build a three-dimensional teaching model of integration of listening, speaking, reading, writing and translating making the best of mobile technology to improve the efficiency of classroom teaching, such as appliances on mobile phones, QQ Zone, WeChat Public Platform, Kingsoft Network Storage Disk and etc. This is to maximize what students learn about English and how they can use it. Afterwards, the new effective model of English teaching to focus on students can be built to replace the traditional language learning model in higher education "Grammar-Translation" .

According to the research report from Xia Hongwen in Hangzhou Normal University on the current situation of using mobile phones to study by university students, students have an urgent need for learning by mobile phones. It holds great potential for students to use mobile phones to study because it accords with the idea in modern society that study is a lifelong matter. The informants have positive attitude towards mobile learning in general, while half of the informants are supposed to be neutral and they tend to transfer from single appliance-focused study method in junior years in university to multiple-equipment-focused methods of study in senior years. This just shows that mobile learning has great prospects for development.

\section{The Main Elements of Research on Mobile English Learning}

It refers to the following four segments.

A. Before Class-mainly focusing on self study by mobile phones

Teachers should inform their students that they can use mobile learning platform to accomplish the tasks assigned of listening, speaking, reading, writing and translating. For example, before the text learning, students should finish listening to the text, then find out their own questions and difficulties during listening, including the grammar question in script and the difficulties in understanding it. This is to encourage students to start the first step to study on their own and to learn what aim should be achieved.

B. In Class-mainly focusing on the interaction between teachers and students

Listening is a stark fault line for students. If students just do exercises under the limited class resources, it is hard for them to achieve the objectives of basic college English requirements. However, if students got familiar with what they should understand or learn and found out clearly what they thought difficult, teachers could have more interactive activities in class without any doubt. For example, the short and long conversations for two students in one group, or give practical feedback and suggestions to students after they have the dictation and group discussion about the details study of the text. This will help students have a clear outline in their mind about how to practice and improve their skills. In the interim, the interaction between teachers and students inspires students' learning initiatives. Just because of that, it is very vital for teachers to design proper interactive activities in class. How to set class activities to stimulate the enthusiasm of students learning should adopt to accord with the data on mobile learning platform and students' actual academic performance to make it work well.

C. After Class-mainly concentrating on the cooperated study in the way of mobile learning 
Guide students to be divided into several English learning groups and hold group activities at regular intervals to discuss given topics in group. For example, the topic could be how to improve reading speed and accuracy of college English, or how to enhance listening ability and how to grasp key words when listening. After discussion, the leader in every group should give a conclusion report according to the actual discussion in their group and upload to QQ Zone or Kingsoft Network Storage Disk. Then their teacher can give conclusive evaluation to the performance of one group and share what they get from discussion with the other groups. Also, teachers could send daily tests or English articles to encourage students to solve problems together. Meanwhile, group difference comparison between groups can be done during the course of group discussion, which will be very beneficial to scientific research and the guidance of practical teaching afterwards.

D. The System of Formative Evaluation throughout Classes

Students should upload their essays to email box, Kingsoft Network Storage Disk, Pigai Writing System or QQ Zone and teachers could correct the essays or leave a message to obtain the information about students progress or performance in the interim and file scientific data and materials. At the same time, the evaluation during the process could help students build active, comprehensive and feasible learning system. The cooperation between students and teachers are the best way for students to learn English better.

\section{The Methods and Main Procedures of Mobile English Learning}

To build the English Teaching and Learning Model with the help of using multimedia tools by literature researches. This may take three month to do the preparations.

B. To compare experimental group and contrast group by respectively using stereo teaching model and traditional teaching model and then record the experiment data and result; the research methods are quantitative research and qualitative research. The pre-test and experiment may last for one semester.

C. To test the two groups at the end of semester; to analyze their differences of academic performance; to sum up the problems existed in teaching models; to continue teaching for the two groups using modified models and record data and result. The post-test with data analysis and model modification may involve one semester.

D. To test the two groups again at the end of semester; to analyze their differences of academic performance; to conclude and write assessment reports and essay.

Detailed procedures are as follows.

Considering the complex differences between different majors, choosing two classes of the same major is a better choice to start with. Then according to the exemplified research to conclude by quantitative and qualitative analysis. First, do a questionnaires survey on the current situation about the usage of students' mobile equipment and mobile learning platforms. Then test one of the two classes as the experimental group and the other as the contrast group. Take listening and reading scores as two issues to test students' ability of learning. Topics in test paper are mainly about campus life, which because the experimental group and contrast group are both from their fresh year in university. After the test, record the data of result and list scores of the two groups in one chart to illustrate their performance clearly.

The next step is to research on various kinds of English learning software or appliances on mobile equipment and platform and choose one or two from them that are suitable and operational for students to practice listening and reading. In the process, collect feedback and suggestions from students about their experience on mobile equipment and make sure they could carry it out without much difficulty. At this period of time, encourage students in experimental group to use mobile devices to launch self-study and organize cooperated study, while teachers try to develop the teaching model in its stereo and multimedia way to guarantee the students' effective performance in class. The traditional teaching model is to be carried out in class of contrast group at the same time. Two weeks before end of this semester, test the students again by the same paper type. Record the results and analysis the distribution of different scores of questions from different groups. Then 
analyze the difficulties and especially the problems of teaching models and interview students for feedback and suggestions. Modify the models in two groups according to the data and information got from the above procedures. The key is to concentrate on the comparing result of the two tests on the second stage of research.

Data from pre-test and post-test is as follows:

Table 1 Scores of Freshman Students from the Experimental Group and Contrast Group

\begin{tabular}{|c|c|c|c|}
\hline Class & $\begin{array}{c}\text { Type I } \\
\text { Listening } \\
\text { (50 points })\end{array}$ & $\begin{array}{c}\text { Type II } \\
\text { Reading } \\
\text { (50 points })\end{array}$ & \\
\hline $\begin{array}{c}\text { Financial } \\
\text { Management } \\
\text { Students } \\
\text { in Experimental } \\
\text { Group }\end{array}$ & 31.4 & 30.4 & \\
\hline $\begin{array}{c}\text { Financial } \\
\text { Management } \\
\text { Students } \\
\text { in Contrast Group }\end{array}$ & 30.8 & 29.8 & \\
\hline
\end{tabular}

Table 2 Scores of the Second Test from the Experimental Group and Contrast Group

\begin{tabular}{|c|c|c|c|}
\hline Class & $\begin{array}{c}\text { Type I } \\
\text { Listening } \\
\text { (50 points) }\end{array}$ & $\begin{array}{c}\text { Type II } \\
\text { Reading } \\
\text { (50 points })\end{array}$ & \\
\hline $\begin{array}{c}\text { Financial } \\
\text { Management } \\
\text { Students } \\
\text { in Experimental } \\
\text { Group }\end{array}$ & 38.6 & 41.2 & \\
\hline $\begin{array}{c}\text { Financial } \\
\text { Management } \\
\text { Students } \\
\text { in Contrast Group }\end{array}$ & 32.1 & 34.7 & \\
\hline
\end{tabular}

You can tell that in the pre-test there is less difference between the scores of experimental group and contrast group in two types of content. However, after implementing the new model of mobile learning with multimedia tools for one semester, their performance in marks of students in experimental group can be recognized as making a great progress, while students in contrast group did their work better but not as good as in experimental group. This shows that students achieved what they should learn in the process of teaching model operation but have great disparity between two groups because of new or traditional teaching model.

\section{Conclusion}

Research on Mobile English Learning focuses on the building of a new comprehensive teaching model which based on mobile technology and multimedia tools. It can help students build their own system of self-study and assessment, including self-adjustment, self-supervision, self-guidance, self-education and active study. If the system worked well, it will also raise the efficiency of in-class teaching and improve the relationship between teachers and students closer and give full support to students all around. The measurable efficiency of the research could obviously be a part of the process of new modern teaching model exploration and an important assistance to guide practice. It is also an essential part of teaching assistance combined with MOOC (massive online 
open courses) from 2012.

Still, with the great progress this new model made, there are limitations in the research. Mobile Learning Model involves several disciplines including mobile communication technology, computer science, pedagogy and psychology. Although we have paid enough attention to the importance of Mobile Learning and Mobile Education, researches and relevant technology on it still fall behind from the urgent need of students English learning and modern education development. China is still in the course of exploration without actual operation in real teaching system of practice. We should attach great importance to the development of this new teaching model and speed up the progress of China' s education information development.

\section{References:}

[1] Garrison, D. R. E-learning in the 21th century: A framework for research and practice[M]. New York: Taylor \& Francis, 2003.

[2] Richey, R. C. Reflections on the 2008 AECT Definitions of the Field [J]. Technology Trends, 2008(1).

[3] Kathleen F. Upside Down and Inside Out: Flip Your Classroom to Improve Student Learning[J]. Learning and Leading with Technology, 2012 (6). 